\title{
Краснова И.А.
}

\author{
Проявление симптомов языковой аналогичности \\ оригинальных и переводных публицистических текстов \\ при переводе с немецкого языка на русский
}

\author{
Krasnova I.A. \\ The display of symptoms of the language analogy based \\ on original and translated publicistic texts in \\ translation from German into Russian
}

Статья посвящена описанию опыта реализации авторской системы симптомов воспроизведения лексической семантики оригинала в переводе. Исследование проводится на примере публицистического дискурса. Доказано преобладание симптома равнокатегориальной лексико-семантической эквивалентности, что свидетельствует о том, что публицистические тексты, как тексты, построенные на фактах, обладают особым уровнем клишированности Ключевые слова: переводческая деятельность, исходный текст, переводной текст, эквивалентный перевод, семантико-структурная аналогичность

\section{Краснова Ирина Александровна}

Кандидат филологических наук, доцент

Московский государственный областной

университет

г. Москва, ул. Радио, 10 A

\begin{abstract}
The article describes the author's experience in the system implementation of the symptoms reproduction of lexical semantics of the original text in the translation. The study is conducted on the example of publicistic discourse. It proved the predominance of the symptom of the the same categorical lexical semantics equivalence, which indicates that the publicistic texts as the factual texts have the particular cliche level
\end{abstract}

Key words: translation activity, original text, translated text, equivalent translation, semanticstructural analogy

\author{
Krasnova Irina Alexandrovna \\ Candidate of Philological Sciences, Associate \\ Professor \\ Moscow region state university \\ Moscow, Radio st., $10 \mathrm{~A}$
}

На фоне постоянно расширяющегося информационного пространства неуклонно возрастает роль переводческой деятельности. В этом соотношении стоит особенно подчеркнуть значение и важность перевода в многоязычной коммуникации вследствие обострения языковых проблем на фоне поиска «идеальных» вариантов перевода того или иного сообщения.

В современных условиях значительно возросли требования к переводческой деятельности, особенно в техническом, коммерческом, дипломатическом, публицистическом (СМИ), юридическом, военном дискурсах. Допущенные не- 
точности при переводе такого рода текстов могут иметь самые серьезные последствия - материальные потери, политические конфликты, человеческие жертвы и т.д.

Основной и главной проблемой перевода является соблюдение должной меры языковой (семантико-структурной) аналогичности исходного теста (далее -ИТ) и переводного текста (далее - ПТ). Качественный (эквивалентный) перевод может иметь самую разную степень близости к оригиналу в языковом плане - от перевода «слово в слово» (буквализм) до полного отсутствия языковой аналогичности.

Ученые давно обратили внимание на такого рода «неравномерность» перевода. В этой связи профессором В.Н. Комиссаровым была создана модель уровней эквивалентности [Комиссаров, 1973, с. 75-157], в которой автор использовал продуктивную идею выделения последовательных переводческих шагов, или уровней перевода. Данная модель стала большим шагом вперед в определении сущности переводческой эквивалентности, однако следует отметить ее ограниченность в прикладном плане [2, с. 7].

Нами была разработана альтернативная, более «инструментальная», удобная в обращении процедура измерения языковой (семантико-структурной) аналогичности ИТ и ПТ. Ее основу составляют четыре симптома, которые описывают способы передачи значений лексических единиц в переводе. Соответствующая обработка симптомов позволяет оценить степень языковой аналогичности ИТ и ПТ [Подр. см.: 2].

На основе анализа переводов текстов различных жанров с немецкого языка на русский стало возможным выделить четыре вида воспроизведения лексической семантики оригинала в переводе:

1. Равнокатегориальная лексико-семантическая эквивалентность (равн. КЛСЭ) - наблюдается сохранение семантики и категориально-морфологических признаков частей речи.

2. Разнокатегориальная лексико-семантическая эквивалентность (разн. КЛСЭ) - наблюдается совпадение лексической семантики, но с несовпадением категориально-морфологических признаков единиц ИТ и ПТ.

3. Перераспределение лексической семантики - при переводе происходит перегруппировка семантических компонентов: по-иному распределяются морфемы, лексемы, синтагмы.

4. Адекватная лексико-семантическая замена - единица ИТ заменяется единицей ПТ с иным лексическим значением, но с аналогичным функциональным потенциалом.

Настоящая статья посвящена описанию опыта реализации вышеозначенных видов воспроизведения семантики оригинала в переводе на примере публицистического дискурса.

Следует отметить, что сложность перевода публицистических текстов заключается в соблюдении главного требования к переводу - достаточной, оптимальной меры языковой аналогичности. Это не всегда удается по причине клишированности такого рода текстов, наличия в них «модных слов», которые в 
большинстве своем являются заимствованными, а также большого количества фразеологизмов.

Рассмотрим каждый из симптомов по отдельности на примере оригинальных немецкоязычных публицистических текстов в статьях 2013 года «Ein Reiseland für Russen / Страна для российских туристов»и «Wie isst Deutschland? / Что едят в Германии?» из он-лайн версии журнала «Deutschland» и их переводов, опубликованных в русскоязычной версии [3; 4]:

Seit der Zarenzeit ist Deutschland für Russen ein beliebtes Urlaubsziel: Luise von Baden heiratete als Elisabeta 1793 den späteren Zar Alexander I. - die erste von mehreren Ehen zwischen den Romanows und dem Herrscherhaus des Fürstentums Baden. So wurde die Petersburger Gesellschaft auf den Kurort Baden-Baden aufmerksam.

Fjodor Dostojewski war gleichfalls passionierter Deutschland-Tourist, der ausgiebig die Heilbäder bereiste - neben Baden-Baden auch Bad Ems, Bad Homburg vor der Höhe und Wiesbaden, wo er seine gesamte Reisekasse verspielte.

Namen deutscher Kurorte haben für russische Ohren immer noch einen guten Klang, weil sie in der klassischen Literatur häufig erwähnt werden. Doch als Ferienziele spielen sie im Zeitalter des Massentourismus keine große Rolle mehr. Nur Baden-Baden zieht noch in nennenswertem Umfang russische Gäste an: Sie stellen mit jährlich rund 50000 Übernachtungen die zweitgrößte Urlaubergruppe nach US-Amerikanern. Jüngere Russen zieht es jedoch vor allem in deutsche Großstädte.

Wobei die russischen Gäste zumeist ganze Regionen besuchen: Zwei Drittel absolvieren Rundreisen durch die Bundesrepublik, was nur ein Fünftel der Deutschland-Touristen aus dem übrigen Europa macht. 15 Prozent der russischen Gäste wollen sich am Wasser oder in den Bergen erholen; 12 Prozent kommen, um Verwandte oder Freunde zu besuchen.

Gesundheit ist ihnen ebenfalls viel wert: Medizinisch motivierte Besuche sind das am schnellsten wachsende Segment des
Еще с царских времен Германия сохраняет популярность среди российских туристов. Луиза Баденская, приняв имя Елизавета, в 1793 г. вышла замуж за будущего царя Александра I - это был первый брак между представителями рода Романовых и маркграфства Баден, на ним последовали и другие. Так петербургское общество обратило внимание на курорт Баден-Баден.

Федор Достоевский также очень любил путешествовать по Германии, много раз посещал курорты с лечебными водами: Баден-Баден, Бад-Эмс, Бад-Хомбург и Висбаден, где проиграл все свои деньги. Названия германских курортов попрежнему сладкозвучны для россиян, так как они часто упоминаются в классической литературе. Но в качестве цели для дальних путешествий в нынешнюю эпоху массового туризма они уже не играют большой роли. Лишь Баден- Баден привлекает еще российских гостей в пределах, достойных упоминания. Ежегодно на их долю приходится около 50000 ночевок - второй по численности показатель после туристов из США. Однако более молодых россиян тянет прежде всего в большие германские города.

При этом российские туристы посещают в большинстве случаев целые регионы: две трети из них совершают обзорные туры по Федеративной Республике, так поступает лишь пятая часть туристов из остальных европейских стран. 15 проц. российских гостей хотят отдохнуть у воды или в горах; 12 проц. приезжают навестить родственников или друзей.

Здоровью они также уделяют большое внимание. Поездки с целью лечения самый быстроразвивающийся сегмент на германском туристическом рынке. В 
deutschen Reisemarkts. 2011 ließen sich in Deutschland rund 340000 ausländische Gäste behandeln; ihre Zahl hat sich laut DZT im Vergleich zum Vorjahr mehr als verdoppelt. Aus Sicht der Kliniken sind arabische und russische Gäste am stärksten an ihrem Dienstleistungsangebot interessiert.

(Oliver Heilwagen. Ein Reiseland für Russen)

Die Studie wurde von der Deutschen Gesellschaft für Ernährung (DGE) vorgelegt Ihre Experten bemängeln vor allem den sehr hohen Fleischverzehr. Dieser trage zwar zu einer guten Versorgung mit Proteinen sowie einigen Vitaminen und Spurenelementen bei, führe aber zu einer übermäßigen Aufnahme von Cholesterin und gesättigten Fettsäuren. Abgesehen davon erhöht üppiger Fleischkonsum das Darmkrebs-Risiko. Mehr als 300 bis 600 Gramm Fleisch pro Woche sollte man nicht essen, raten die DGE-Fachleute. Zurzeit verspeisen deutsche Frauen gut 570 Gramm Fleisch wöchentlich und Männer etwa das Doppelte.

(Wie isst Deutschland?)
2011 г. в Германии проходили лечение около 340000 иностранных туристов; их число по сравнению с предыдущим годом, по данным DZT, выросло более чем в два раза. C точки зрения клиник, больше всего в их услугах заинтересованы арабские и российские туристы.

(Оливер Хайльваген. Страна для российских туристов)

Исследование проводилось специалистами из Германского общества питания (DGE).

Эксперты отмечают, прежде всего, слишком большое количество мяса в рационе. С одной стороны, мясо обеспечивает организм белками, витаминами и микроэлементами. С другой стороны, эта пищевая привычка приводит к излишне большому потреблению холестеринов и насыщенных жирных кислот. Кроме того, избыточное потребление мяса вызывает риск заболевания раком кишечника. Эксперты DGE не рекомендуют съедать больше 300-600 г мяса в неделю. А в настоящее время немецкие женщины съедают 570 г мяса в неделю, а мужчины - вдвое больше.

(Что едят в Германии?)

\section{1) Равнокатегориальная лексико-семантическая эквивалентность} (равн. КЛСЭ) - с сохранением семантики и категориально-морфологических признаков частей речи.

Seit der Zarenzeit ist Deutschland für Russen ein beliebtes Urlaubsziel: Luise von Baden heiratete als Elisabeta 1793 den späteren Zar Alexander I. - die erste von mehreren Ehen zwischen den Romanows und dem Herrscherhaus des Fürstentums Baden. So wurde die Petersburger Gesellschaft auf den Kurort Baden-Baden aufmerksam.

(Oliver Heilwagen. Ein Reiseland für Russen)
Еще с царских времен Германия сохраняет популярность среди российских туристов. Луиза Баденская, приняв имя Елизавета, в 1793 г. вышла замуж за будущего царя Александра I - это был первый брак между представителями рода Романовых и маркграфства Баден. Так петербургское общество обратило внимание на курорт Баден-Баден.

(Оливер Хайльваген. Страна для российских туристов) 
В данном примере присутствуют 17 равнокатегориальных лексико-семантических эквивалента:

Seit $\rightarrow$ C; Deutschland $\rightarrow$ Германия; Luise von Baden $\rightarrow$ Луиза Баденская; Zar Alexander I $\rightarrow$ царя Александра I; erste $\rightarrow$ первый; zwischen $\rightarrow$ между; Romanows $\rightarrow$ Романовых; und $\rightarrow$ и; Herrscherhaus $\rightarrow$ представителями; Fürstentums $\rightarrow$ маркграфства; Baden $\rightarrow$ Баден; So $\rightarrow$ так; wurde aufmerksam $\rightarrow$ обратило внимание на...; Petersburger $\rightarrow$ петербургское; Gesellschaft $\rightarrow$ общество; Kurort $\rightarrow$ курорт; Baden-Baden $\rightarrow$ Баден-Баден.

При этом следует отметить, что эквивалентом исходного слова следует считать не отдельные единицы правой части, а их совокупность, точнее их «среднее значение», то общее, что содержится в каждой из них.

\section{2) Разнокатегориальная лексико-семантическая эквивалентность} (разн. КЛСЭ) - совпадение лексической семантики единиц ИТ и ПТ, но несовпадение их категориально-морфологических признаков частей речи.

\section{1. Сложн. сущ. $\rightarrow$ сущ. + сущ. с предл.}

Doch als Ferienziele spielen sie im Zeitalter des Massentourismus keine große Rolle mehr.

(Oliver Heilwagen. Ein Reiseland für Russen)

\section{2. Сущ. $\rightarrow$ наречие}

Zurzeit verspeisen deutsche Frauen gut 570 Gramm Fleisch wöchentlich und Männer etwa das Doppelte.

(Wie isst Deutschland?)

\section{3. Сложн. сущ. $\rightarrow$ прил + сущ.}

Jüngere Russen zieht es jedoch vor allem in deutsche Großstädte.

Seit der Zarenzeit ist Deutschland für Russen ein beliebtes Urlaubsziel.

(Oliver Heilwagen. Ein Reiseland für Russen)

\section{4. Нареч. $\rightarrow$ сущ. с предл.}

Wobei die russischen Gäste zumeist ganze Regionen besuchen.

(Oliver Heilwagen. Ein Reiseland für Russen)
Но в качестве цели для дальних путешествий в нынешнюю эпоху массового туризма они уже не играют большой роли.

(Оливер Хайльваген. Страна для российских туристов)

А в настоящее время немецкие женщины съедают 570 г мяса в неделю, а мужчины - вдвое больше. (Что едят в Германии?)

Однако более молодых россиян тянет прежде всего в большие германские города.

Еще с царских времен Германия сохраняет популярность среди российских туристов.

(Оливер Хайльваген. Страна для российских туристов)

При этом российские туристы посещают в большинстве случаев целые регионы.

(Оливер Хайльваген. Страна для российских туристов) 
3) Перераспределение лексической семантики - при переводе происходит перегруппировка семантических компонентов, содержание получает иную группировку: по-иному распределяются морфемы, лексемы, синтагмы, семантика одного слова может воспроизводиться несколькими лексическими единицами или наоборот.

Fjodor Dostojewski war gleichfalls passionierter Deutschland-Tourist. Namen deutscher Kurorte haben für russische Ohren immer noch einen guten Klang, weil sie in der klassischen Literatur häufig erwähnt werden.

(Oliver Heilwagen. Ein Reiseland für Russen)
Федор Достоевский также очень любил путешествовать по Германии.

Названия германских курортов попрежнему сладкозвучны для россиян, так как они часто упоминаются в классической литературе.

(Оливер Хайльваген. Страна для российских туристов)

Часто перераспределение семантических компонентов подразумевает под семантическую трансформацию высказывания, при которой имеет место лексическое свертывание и лексическое развертывание как и в рассматриваемом выше примере.

4) Адекватная лексико-семантическая замена - с полным отсутствием семантического инварианта - прием, заключающийся в замене единицы ИТ единицей ПТ с иным лексическим значением, но с аналогичным функциональным потенциалом, что позволяет воспроизвести речевое воздействие ИТ (потеряв эквивалентность прямых значений, сохранить эквивалентность значений образных).

В переводах такого рода определенная часть исходного содержания заменяется другим содержанием, которое способно выполнить те же речевые функции.

Gesundheit ist ihnen ebenfalls viel wert. (Oliver Heilwagen. Ein Reiseland für Russen)
Здоровью они также уделяют большое внимание.

(Оливер Хайльваген. Страна для российских туристов)

На рассмотренных примерах, можно проследить, как и насколько симптомы семантико-структурной аналогичности характеризуют степень отклонения ИТ от ПТ: равн КЛСЭ указывает на максимальную степень близости, адекватная ЛСЗ - на ее отсутствие. Для наглдности изобразим полученные результаты в виде диаграммы - рисунок 1 . 


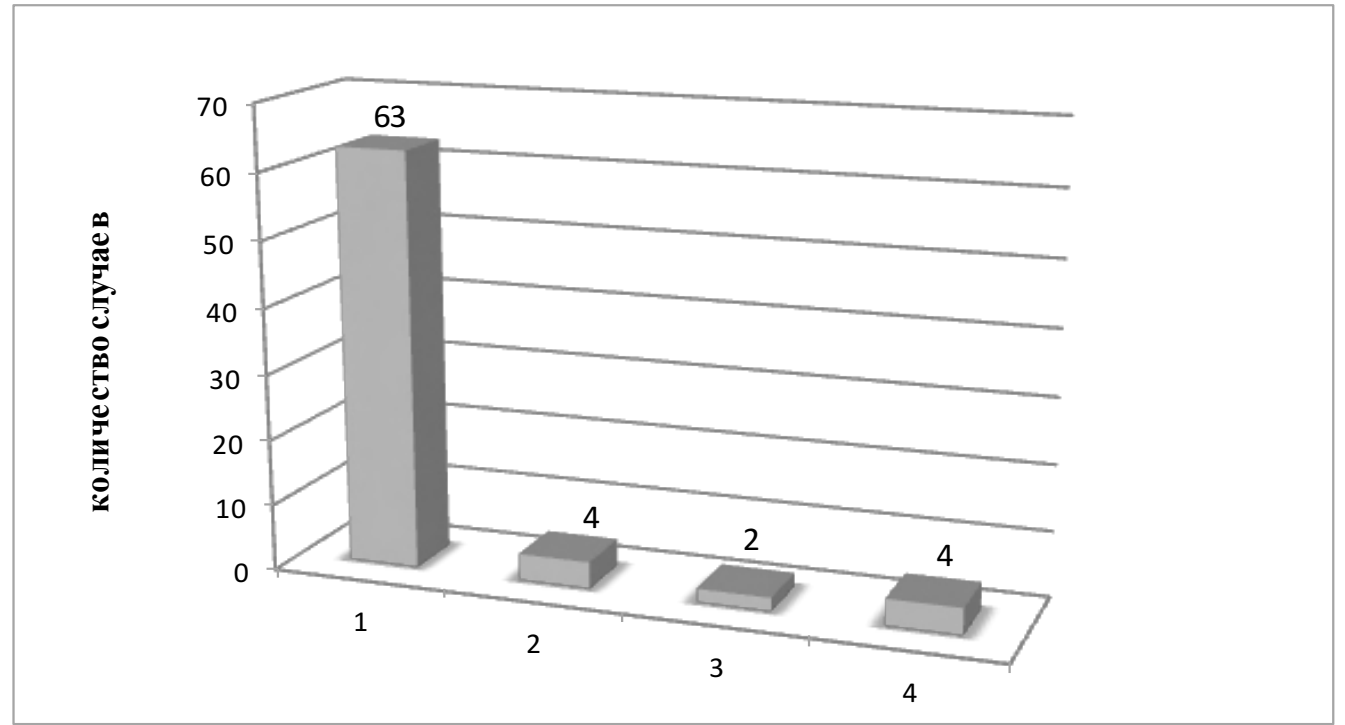

Рис. 1: 1 - Равн. КЛСЭ; 2 - разн. КЛСЭ; 3 - перераспределение лексич. семантики; 4- адекватные лексико-семантические замены

Из проведенного анализа стало ясно, что симптом равн. КЛСЭ по сравнению с разн. КЛСЭ, перераспределением лексич. семантики и адекватными лексико-семантическими заменами встречается намного чаще остальных (63\%), что свидетельствует о том, что публицистические тексты как тексты, построенные на фактах, в отличие от остальных, обладают особым уровнем клишированности.

Но, несмотря на это, не стоит забывать о специфичности данного жанра и о возможных «трансформациях», возникающих при переводе слова или выражения, не имеющего аналога в ПТ.

\section{Список используемых источников:}

1. Комиссаров В.Н. Слово о переводе. М.: Международные отношения, 1973. 216 c.

2. Краснова И.А. Измерение семантико-структурной аналогичности оригинала и перевода (на материале текстов различных жанров с немецкого языка на русский). Saarbrücken (Германия): LAP LAMBERT, 2012. 164 c.

3. Онлайн-версия статьи Страна для российских туристов.

URL: https://www.deutschland.de/de/topic/leben/mobilitat-reise/ein-reiseland-fur-russen 4. Онлайн-версия статьи «Что едят в Германии?

URL: https://www.deutschland.de/de/topic/leben/lifestyle-kulinarik/wie-isst-deutschland

\section{(C) 2016, Краснова И.А.}

Проявление симптомов языковой аналогичности оригинальных и переводных публицистических текстов при переводе с немецкого языка на русский
(C) 2016, Krasnova I.A.

The display of symptoms of the language analogy based on original and translated publicistic texts in translation from German into Russian 